\title{
Ischemic Stroke Following Calloselasma rhodostoma Snakebite: A Rare Case Report
}

\author{
Rizaldy Taslim Pinzon (D) ${ }^{1,2}$, Radian Adhiputra Antonius $\mathbb{D}^{\prime}$, Vanessa Veronica $\mathbb{D}^{\prime}$ \\ 'Faculty of Medicine, Duta Wacana Christian University, Yogyakarta, Indonesia; ${ }^{2}$ Department of Neurology, Bethesda Hospital, Yogyakarta, Indonesia \\ Correspondence: Rizaldy Taslim Pinzon, Faculty of Medicine, Duta Wacana Christian University, Doctor Wahidin Sudirohusodo street number 5-25, \\ Yogyakarta, 55224, Indonesia, Email drpinzon17@gmail.com
}

\begin{abstract}
Background: Ischemic stroke following a snakebite is a rare case. Snake venom consists of multiple components which can cause various symptoms and consequences. We report a case of ischemic stroke following Calloselasma rhodostoma snakebite, and this study was the first to report a case of ischemic stroke after snakebite in Indonesia.

Case Presentation: A 72-year-old Mongoloid male presented with a history of snakebite one day before hospital admission with a swollen right lower leg with no history of hypertension, diabetes mellitus, or heart disease. The patient was conscious. His temperature was $36.5^{\circ} \mathrm{C}$, pulse rate was 90 beats per minute, respiration rate was 30 breaths per minute, and blood pressure was 162/109 mmHg. The neurological examination showed left-side weakness and headache, with blood laboratory results showing prolonged prothrombin time (PT) and activated partial thromboplastin time (aPTT), leucocytosis, thrombocytopenia, and low haemoglobin. A computerized tomogram (CT) scan of the brain was taken, which revealed a sign of infarct in the pericallosal of the right lateral periventricular anterior horn.
\end{abstract}

Conclusion: Although ischemic stroke following a snakebite is uncommon, it must be considered and monitored.

Keywords: Calloselasma rhodostoma, Viperidae, ischemic stroke, snakebite

\section{Background}

Snakebites are prevalent and often fatal, particularly in rural parts of tropical developing countries. ${ }^{1}$ In Indonesia, the species responsible for most bites from Viperidae families, are Calloselasma rhodostoma, primarily found in Java and Madura Island, while Daboia siamensis in East Java, Komodo, Flores, and Lomblen. ${ }^{2}$ Local poisoning is the most prevalent symptom of a viper bite, followed by neurotoxicity, coagulopathy, and hemostatic disorders. Snakebite cases resulting in cerebrovascular disorders are most frequently hemorrhagic but rarely ischemic. ${ }^{3}$

There were only a few snakebite cases in Indonesia, all based on hospital reports. ${ }^{4}$ Incidence of strokes after snakebite is a scarce case. There are only a few cases in Asia, particularly in India. ${ }^{5,6}$ In Indonesia, no single case was reported in any journal. Despite rare cases of snake attacks, the lack of published cases of ischemic stroke following snakebite is of great interest.

\section{Case Presentation}

A 72-year-old Mongoloid male was admitted to the emergency department at Bethesda Hospital, Yogyakarta, Indonesia with a history of snakebite in the right lower leg one day before hospital admission. The snake was identified as a Malayan Pit Viper (Calloselasma rhodostoma). He appeared with a swollen right leg and fang marks on his right leg (Figure 1). Two vials of local antivenom serum (ASV) in $500 \mathrm{~mL}$ of sodium chloride were administered within five hours as the initial treatment.

On admission, the patient was conscious with 15 GCS (Glasgow Coma Scale). The patient's temperature was $36.5^{\circ} \mathrm{C}$, the pulse rate was 90 beats per minute, the respiration rate was 30 breaths per minute, and the blood pressure was 162/ $109 \mathrm{mmHg}$. The neurological examination showed left-side weakness and headache. The patient was suffering from severe pain with a burning sensation at the snakebite mark and was treated with intravenous ketorolac $10 \mathrm{mg}$ and 


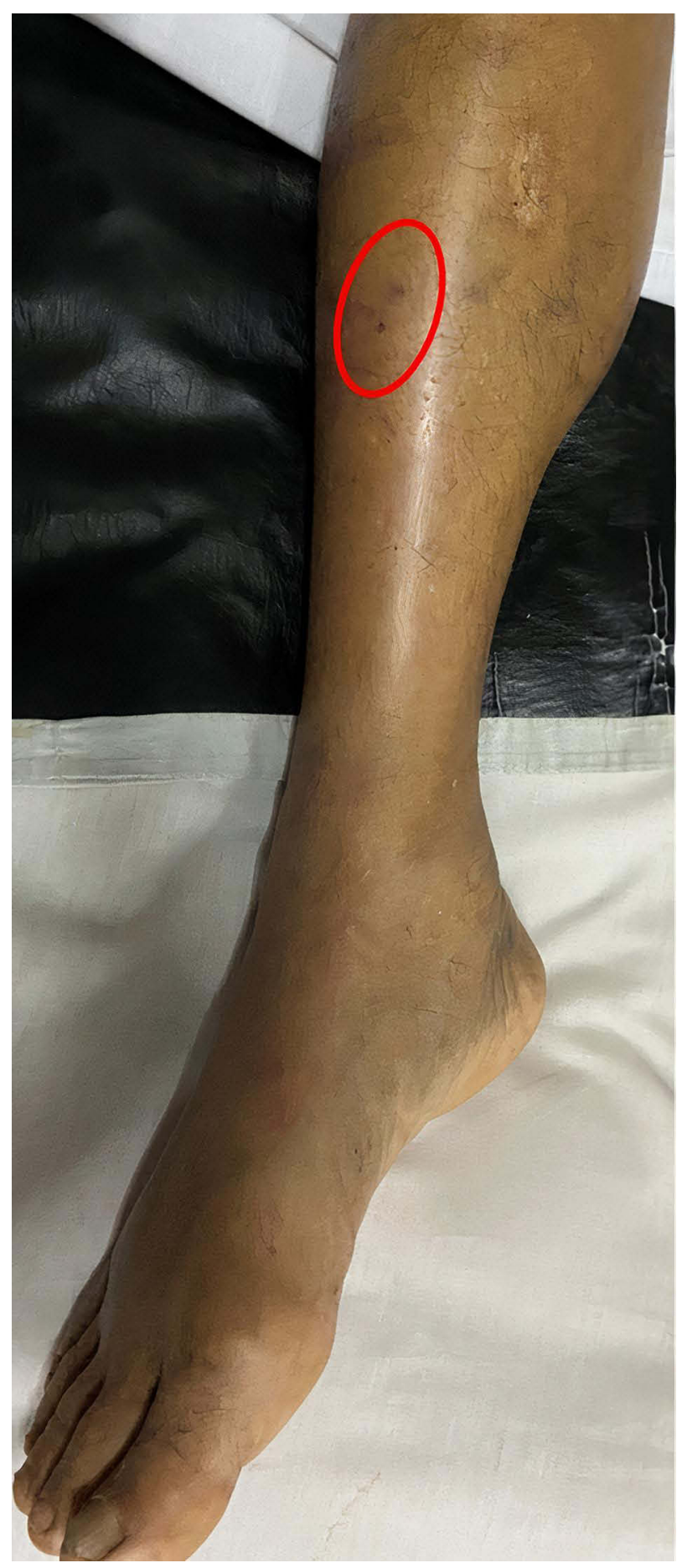

Figure I A swollen right leg with fang marks (fang marks were circled in red).

ceftriaxone one gram twice a day. The patient and patient's family had no history of hypertension, diabetes mellitus, or heart disease.

The blood laboratory results were presented with; leucocytosis, thrombocytopenia, low haemoglobin, high urea concentration, and normal creatinine serum. The patient was transfused with one bag of a packed red cell (PRC) due to low haemoglobin and thrombocyte. The values of prothrombin time (PT) and activated partial thromboplastin time (aPTT) were prolonged. His computerized tomogram (CT) scan showed an ischemic infarct in the pericallosal of the right lateral periventricular anterior horn (Figure 2). An electrocardiogram (ECG) revealed sinus rhythm with no left 


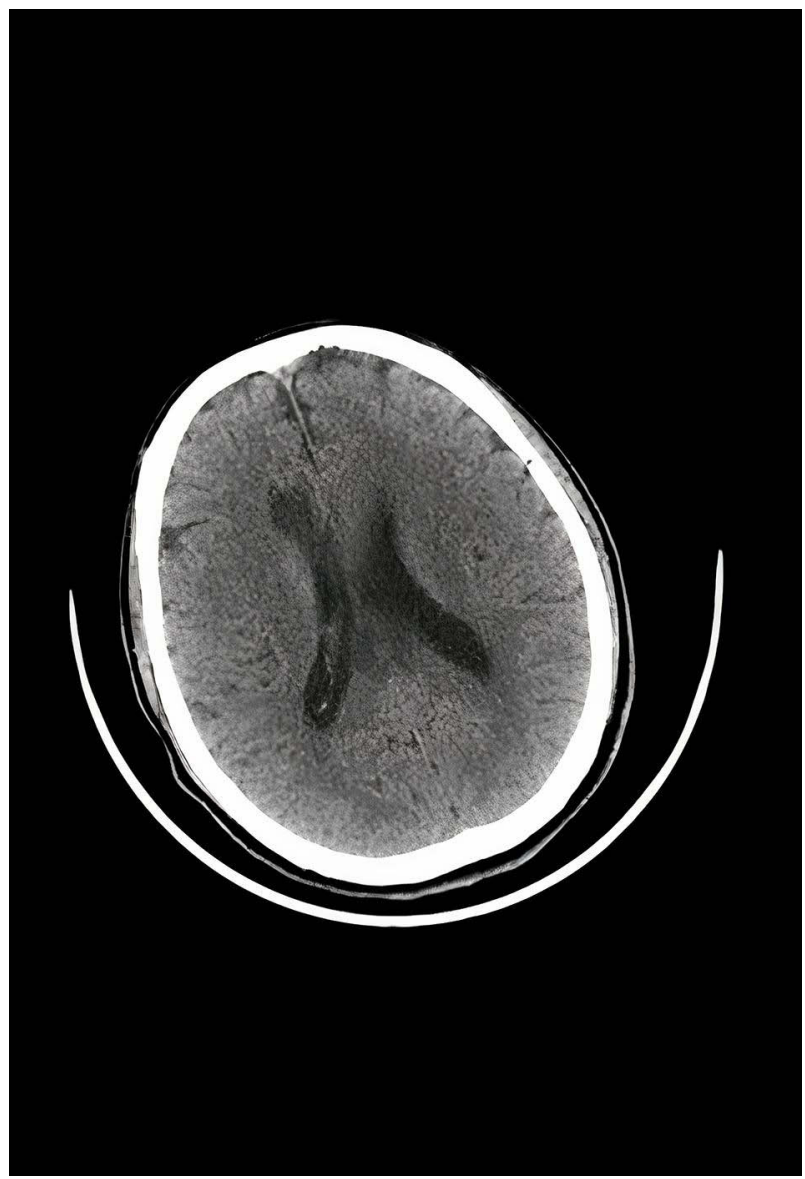

Figure 2 CT scan showed an ischemic infarct in the pericallosal of the right lateral periventricular anterior horn.

ventricle enlargement. The patient's condition improved and became more stable two days after being bitten by a snake. Although haemoglobin and thrombocyte levels had increased, they remained low. As such, further monitoring was required. After the ninth day of treatment, the patient was discharged and instructed to monitor his condition regularly.

\section{Discussion}

To our knowledge, this study was the first to report a case of ischemic stroke after snakebite in Indonesia. The pathological consequences of envenoming can vary and be complex due to the variety of poisonous components found in snake venom; variables such as bite location and amount of venom released can also vary. ${ }^{7}$ After being bitten by a Viperidae, patients may experience a burning or throbbing feeling in the bite area, and local swelling occurs rapidly around the bite mark, perhaps affecting the entire limbs and adjacent trunk. ${ }^{8}$ The clinical significance of recognizing the type of snake that bites can assist health care professionals in providing and administering proper treatments, such as antivenom serum. ${ }^{9}$ Because antivenom serum is only effective against a limited number of venomous snakes and has the potential for lethal adverse effects such as fatal allergic reactions, it should not be used to treat bites from non-venomous snakes, especially considering the scarcity and high cost of venom in many countries. ${ }^{10}$

Leukocytosis was detected in the laboratory, indicating that the body responded to the toxin's effects with stress and inflammation. ${ }^{11}$ Additionally, snakebites were related with anemia, thrombocytopenia, hypofibrinogenemia, leukocytosis, coagulopathy, proteinuria, and azotemia. ${ }^{12}$ In a study in India, most patients of all genders developed hypertension following a snakebite, despite the venom's ability to reduce blood pressure, impede muscle control, and destroy red cells. ${ }^{13}$ The mechanism of hypertension following a snakebite remained unknown; it is thought that catecholamine in snake venom is released from adrenergic nerve terminals, resulting in hypertension-like symptoms. ${ }^{14}$ The previous 
statement is also supported by the fact that our patient has no history of hypertension, diabetes mellitus, or heart disease. During the acute stage, the effects of snake venom can cause fatal harm to the body, resulting in death if not treated properly. However, with antivenom serum and proper medical treatment, these symptoms can resolve on their own. ${ }^{1}$ However, what sometimes escapes health workers' attention are long-term symptoms that can lead to fatal complications. $^{15}$

The Viperidae venom may cause systemic bleeding because of hemorrhagins in its venom, which damages vascular endothelium ${ }^{1}$ and increased vascular permeability. ${ }^{6}$ Hemorrhagins also develop a microthrombi formation leading to lowgrade disseminated intravascular coagulopathy resulting in ischemia and infarction ${ }^{16}$ due to occlusion of small and large blood vessels. ${ }^{17}$ One of the most abundant components of Viperidae venom is Snake Venom-C-Type Lectin-Related Protein (SV-CLRPs), which inhibits the interaction of clotting factors and various receptors on platelets, immune, and endothelial cells. ${ }^{18}$ The pro-coagulant properties of serine proteinases and snake venom metalloproteinases (SVMPs) result in defibrinogenation and incoagulability. In some cases, the pro-coagulant components of snake venoms or damage to the endothelium lining result in regional thrombosis with subsequent local or remote ischemia events, all of which contribute to the complicated pathophysiology of cardiovascular changes associated with snakebite poisoning. ${ }^{19}$ Endothelial and vascular damage are plausible reasons for cerebral infarction. ${ }^{17}$ Due to the absence of additional risk factors, we believe that our patient's cerebral infarction was caused by toxin-induced vascular spasm and endothelial damage.

\section{Conclusion}

Although ischemic stroke following a snakebite is uncommon, it must be considered and monitored.

\section{Data Sharing Statement}

Data sharing does not apply to this article as no datasets were generated or analyzed during the current study.

\section{Ethical Approval}

This study requires no approval from the ethical committee due to the nature of this case report. However, this study has obtained permission from the Bethesda Hospital Research and Development Department. In accordance with the Declaration of Helsinki, the patient's identity was hidden.

\section{Consent for Publication}

Written informed consent was obtained from the patient to publish this case report and any accompanying images.

\section{Acknowledgments}

We want to express our gratitude to the patient for contributing to this case report.

\section{Author Contributions}

All authors made a significant contribution to the work reported, whether that is in the conception, study design, execution, acquisition of data, analysis and interpretation, or in all these areas; took part in drafting, revising or critically reviewing the article; gave final approval of the version to be published; have agreed on the journal to which the article has been submitted; and agree to be accountable for all aspects of the work.

\section{Funding}

The authors fully funded this study.

\section{Disclosure}

The authors declare that they have no competing interests. 


\section{References}

1. Warrell DA. Snake bite. Lancet. 2010;375(9708):77-88. doi:10.1016/S0140-6736(09)61754-2

2. World Health Organization [homepage on the Internet]. Guidelines for the management of snakebites, 2nd ed; 2018. Available from: https://apps. who.int/iris/handle/10665/249547. Accessed August 19, 2021.

3. Paul R, Sasane SA. Rare ischemic stroke presentation after viper bite-a case report. Int J Neurol Res. 2017;3(1):335-337. doi:10.17554/j.issn.23135611.2017.03.65

4. Adiwinata R, Nelwan EJ. Snakebite in Indonesia. Acta Med Indones. 2015;47(4):358-365.

5. Pothukuchi VK, Kumar A, Teja C, Verma A. A rare case series of ischemic stroke following Russell's viper snake bite in India. Acta Med Indones. 2017;49(4):343-346.

6. Paul G, Paul BS, Puri S. Snake bite and stroke: our experience of two cases. Indian J Crit Care Med. 2014;18(4):257-258. doi:10.4103/09725229.130585

7. Alirol E, Sharma SK, Bawaskar HS, Kuch U, Chappuis F. Snake bite in South Asia: a review. PLoS Negl Trop Dis. 2010;4(1):e603. doi:10.1371/ journal.pntd.0000603

8. Mehta SR, Sashindran VK. Clinical features and management of snake bite. Med J Armed Forces India. 2002;58(3):247-249. doi:10.1016/S03771237(02)80140-X

9. Williams HF, Layfield HJ, Vallance T, et al. The urgent need to develop novel strategies for the diagnosis and treatment of snakebites. Toxins. 2019;11(6):363. doi:10.3390/toxins11060363

10. Bolon I, Durso AM, Botero Mesa S, et al. Identifying the snake: first scoping review on practices of communities and healthcare providers confronted with snakebite across the world. PLoS One. 2020;15(3):e0229989. doi:10.1371/journal.pone.0229989

11. Akoz A, Yildiz V, Orun S, Turkdogan KA, Duman A. Management of poisonous snake bites: analysis of 29 cases. J Clin Exp Investig. 2018;9 (4):140-144. doi:10.5799/jcei/3998

12. Elbey B, Baykal B, Yazgan ÜC, Zengin Y. The prognostic value of the neutrophil/lymphocyte ratio in patients with snake bites for clinical outcomes and complications. Saudi J Biol Sci. 2017;24(2):362-366. doi:10.1016/j.sjbs.2015.10.002

13. Natarajan S. Relative incidence of changes in blood pressure in Viper bites. IAIM. 2020;7(6):36-38.

14. Malina T, Krecsak L, Warrell DA. Neurotoxicity and hypertension following European adder (Vipera berus berus) bites in Hungary: case report and review. Qjm. 2008;101(10):801-806. doi:10.1093/qjmed/hcn079

15. Jayawardana S, Arambepola C, Chang T, Gnanathasan A. Long-term health complications following snake envenoming. J Multidiscip Healthc. 2018;11:279-285. doi:10.2147/JMDH.S126648

16. Prasad UDN, Bandara JMRP, Senanayake HMS. Multiple cerebral and cerebellar infarctions following Russell's Viper (Daboia Russelii) envenomation - a case report. Clin Med Rev Case Reports. 2020;7(6):1-3.

17. Panicker JN, Madhusudanan S. Cerebral infarction in a young male following viper envenomation. J Assoc Physicians India. 2000;48(7):744-745.

18. Eble JA. Structurally robust and functionally highly versatile-C-type lectin (-related) proteins in snake venoms. Toxins. 2019;11(3):136. doi:10.3390/toxins 11030136

19. Gutiérrez JM, Escalante T, Rucavado A, Herrera C. Hemorrhage caused by snake venom metalloproteinases: a journey of discovery and understanding. Toxins. 2016;8(4):93. doi:10.3390/toxins 8040093

Open Access Emergency Medicine

Dovepress

\section{Publish your work in this journal}

The Open Access Emergency Medicine is an international, peer-reviewed, open access journal publishing original research, reports, editorials, reviews and commentaries on all aspects of emergency medicine. The manuscript management system is completely online and includes a very quick and fair peer-review system, which is all easy to use. Visit http://www.dovepress.com/testimonials.php to read real quotes from published authors.

Submit your manuscript here: https://www.dovepress.com/open-access-emergency-medicine-journal 